\title{
Tubercular Uveitis in the Event of HIV Infection about a Case
}

\author{
Abdramane Traoré1, Hamsatou Cisse1, Nagou Tolo1, Djenebou Traoré2, Condé Lassana1, \\ Assétou Soukho Kaya², Abasse Sanogo², Bréhima B. Berthé2, Ibrahima Amadou Dembélé2, \\ Mahamadou Saliou ${ }^{3}$, Djibril Sy², Nanco Doumbia4, Sekou Mamadou Cissé2, Boubacar Zana Cisse², \\ Mamadou Dembélé ${ }^{2}$, Abdel Kader Traoré ${ }^{2}$, Hamar Alassane Traoré2
}

\author{
${ }^{1}$ Department of Medicine Sidy Bocar Sall Kati Hospital, Koulikoro, Mali \\ ${ }^{2}$ Department of Internal Medicine at CHU Point G, Bamako, Mali \\ ${ }^{3}$ Department of Internal Medicine of CHU Gabriel Touré, Bamako, Mali \\ ${ }^{4}$ Internal Medicine Service of the Mali Hospital, Bamako, Mali \\ Email: monopolytra@yahoo.fr, monopolytra@gmail.com, assetousouko@yahoo.fr, djibroul@yahoo.fr, \\ traoreabdramane55@yahoo.fr, bbrehima@yahoo.fr, mahamadousaliou75@gmail.com, traoreabdramane55@yahoo.fr, \\ ibadem1@yahoo.fr, tolon@yahoo.fr, traoreak@gmail.com, hassiramadydembele@yahoo.fr, traorhamaralassane@yahoo.fr, \\ lassanaconde@yahoo.fr, docteurdoumbia@gmail.com, cissesekoum@yahoo.fr, boubacarcisse@yahoo.fr, hamsatouc@yahoo.fr
}

How to cite this paper: Traoré, A., Cisse, H., Tolo, N., Traoré, D., Lassana, C., Kaya, A.S., Sanogo, A., Berthé, B.B., Dembélé, I.A., Saliou, M., Sy, D., Doumbia, N., Cissé, S.M., Cisse, B.Z., Dembélé, M., Traoré, A.K. and Traoré, H.A. (2019) Tubercular Uveitis in the Event of HIV Infection about a Case. Journal of Tuberculosis Research, 7, 253-258. https://doi.org/10.4236/jtr.2019.74025

Received: October 7, 2019

Accepted: December 21, 2019

Published: December 24, 2019

Copyright ( 2019 by author(s) and Scientific Research Publishing Inc. This work is licensed under the Creative Commons Attribution International License (CC BY 4.0).

http://creativecommons.org/licenses/by/4.0/ (c) () Open Access

\begin{abstract}
Tuberculosis is an infectious disease caused by Mycobacterium tuberculosis. This disease is the second leading cause of infectious mortality in the world after infection with the human immunodeficiency virus. We report a case of multifocal tuberculosis with neuromuscular and ocular localization in an HIV-1 immunosuppressed patient in clinical and virological failure following therapeutic discontinuation due to non-compliance. This is a 43 -year-old immunocompromised HIV1 patient with a history of cerebral toxoplasmosis in 2016 who consulted for right hemiplegia. These symptoms would go back to about 3 days marked by a deficit of progressive installation of the right hemicorps preceded by diffuse headaches, of moderate intensity without triggering factor radiating to the eyes associated with an intermittent fever with periods of spontaneous remissions, night sweats and chills, non-selective anorexia, non-increasing physical asthenia and unquantified weight loss. Management was 8-month antituberculous treatment, combining the first two months isoniazid (INH), rifampicin (RMP), pyrazinamide (PZN) and ethambutol (EMB), then the next 6 months (INH) and rifampicin (RMP). The reintroduction of the same antiretroviral protocol and a reinforcement of the therapeutic education made it possible to observe a decrease of the viral load. Treatment of ocular involvement was instituted with Timosol 1 drop in the eyes morning and evening and Diclocid $1 \mathrm{mg} / \mathrm{ml}: 1$ drop in the eyes in the morning.
\end{abstract}




\section{Keywords}

Tucerculose/Uveitis

\section{Introduction}

Tuberculosis is an infectious disease caused by a mycobacterium of the Mycobacterium tuberculosis complex. This disease is the second leading cause of infectious mortality in the world after infection with the human immunodeficiency virus [1].

Ocular tuberculosis (TB) is responsible for $5 \%$ to $10 \%$ of cases of ocular inflammation (OI) [2]. Mycobacterium tuberculosis (MT) can affect all structures of the eye without any pathognomonic presentation. Tuberculous uveitis is the most common lesion [2].

Tuberculosis is in most cases multivisceral. Ocular involvement is present in two-thirds of cases [3] [4].

The number of blindness and other eye diseases associated with acquired immunodeficiency syndrome (AIDS) increases as the disease spreads [4] [5]. In France, the prevalence of ocular involvement during HIV is 67\% [6]; in the United States 60\% [7].

In sub-Saharan Africa, the progression of the endemic is constant with 24.7 million people living with HIV-AIDS in 2010 [8]. In Togo, the prevalence of ocular involvement is 60.5\% [9]; in the DRC 64.4\% [3]; Rwanda 55\% [3]; in Senegal $52.23 \%$ [7].

In Mali, TOGO.R in 2013 [10] found eye damage in the course of HIV in $87.3 \%$.

The clinical manifestations of this infection are polymorphic and variable which makes diagnosis difficult.

\section{Method}

This was a case study that allowed us to make a clinical observation on a tuberculous uveitis in an HIV-immunocompromised patient.

OBSERVATION: We report the case of Mr. KC, 43 years old, military who consults for right hemiplegia.

These symptoms would go back to about 3 days marked by a deficit of progressive installation of the right hemicorps preceded by diffuse headaches, of moderate intensity without triggering factor radiating to the eyes associated with an intermittent fever with periods of spontaneous remissions, night sweats and chills, non-selective anorexia, non-increasing physical asthenia and unquantified weight loss.

The physical examination found a Glasgow at $12 / 15$, a disorientation in time and space, a deficit of the right proportional hemi-body, meningeal stiffness, a tonic-clonic crisis without notion of bite of the tongue. 
The evolution is marked by the occurrence of visual blur.

Elsewhere we noted a history of cerebral toxoplasmosis in 2016 and HIV immunodepression at the same time.

The cerebral scanner objectified of small hypodensities with ring enhancement, one of which presents a more or less significant periosessional hypodensity, a diffuse hypodensity of the cerebral parenchyma with obliteration of the cortical furrows contrasting with a moderate quadrivenicular dilatation. After contrast injection, there is a moderate enhancement of the subarachnoid space of the base, an absence of spontaneously visible expansive process and peri-cerebral collection. The medial structures are in place. The cerebral fossa is of normal density and normal morphology. Filling of left mastoid cells. Sine of the well ventilated face. In conclusion, we have the appearance of tomodensitometry in favor of cerebro-meningeal tuberculosis; cerebral toxoplasmosis; left mastoiditis (Figure 1).

The absence of signs of cerebral involvement allowed us to make a macroscopic lumbar puncture that was slightly hazy; microscopy found fresh leucocytes at 202 elements/ul, rare red blood cells, yeasts: absence, bacteria: absence; Gram direct staining is negative. Indian ink noted the absence of cryptococcus; may gram giemsa found lymphocytes at $98 \%$; chemistry found protein at $1.320 \mathrm{~g} / \mathrm{l}(\mathrm{N}$ : $0.1-0.45)$, glucose at $2.10 \mathrm{~g} / \mathrm{l}(\mathrm{N}: 2 / 3$ of the blood glucose $)$, chlorine at $125.4 \mathrm{~g} / \mathrm{l}$ $(\mathrm{N}: 110$ - 120), lactate: $2.15 \mathrm{~g} / \mathrm{l}(\mathrm{N}: 1.2$ - 6.7), cerebrospinal fluid culture is sterile.

The central blood glucose was $4.17 \mathrm{mmol} / \mathrm{l}$.

Since there was no symptomatology made of cough, the search for pulmonary tuberculosis was carried out; a chest $\mathrm{x}$-ray is normal, the search for acid-fast bacilli is negative; intradermal reaction to tuberculin at $6 \mathrm{~mm}$

The level of CD4 T lymphocytes was not made because of its unavailability, but the viral load on admission was 526,000 copies $/ \mathrm{ml}$.

Blood count number found a hemoglobin level of $9.2 \mathrm{~g} / \mathrm{dl}$, a hematocrit of $27.6 \%$, white blood cell at $2900 / \mathrm{mm}^{3}$, red blood cell at $3,900,000 / \mathrm{mm}^{3}$, the red blood cell volume at $89 \mathrm{fl}$, Plaquette à $188,000 / \mathrm{mm}^{3}$, the corpuscular concentration at $33.3 \mathrm{~g} / \mathrm{dl}$, lymphocytes at $1720 / \mathrm{mm}^{3}$, polynuclear neutrophils at $710 / \mathrm{mm}^{3}$, polynuclear basophils at $70 \mathrm{~mm}^{3}$, monocytes at $340 \mathrm{~mm}^{3}$, lymphocytes at $1720 / \mathrm{mm}^{3}$. In front of normochromic normochromic anemia we asked the reticulocytes which come back to $35,400 / \mathrm{mm}^{3}$.

The ophthalmological consultation associated with an eye fund was requested; after this consultation the ophthalmologist to suggest to send the patient to retinophoto which objectifies posterior uveitis (Figure 2).

We have been diagnosed with multifocal tuberculosis with neuromuscular and ocular localization in an HIV-1 immunosuppressed patient in clinical and virological failure following therapeutic discontinuation due to non-observance. Management was 8-month antituberculous treatment, combining the first two months isoniazid (INH), rifampicin (RMP), pyrazinamide (PZN) and ethambutol (EMB), then the next 6 months (INH) and (RMP). The reintroduction of the same antiretroviral protocol and a reinforcement of the therapeutic education made it 


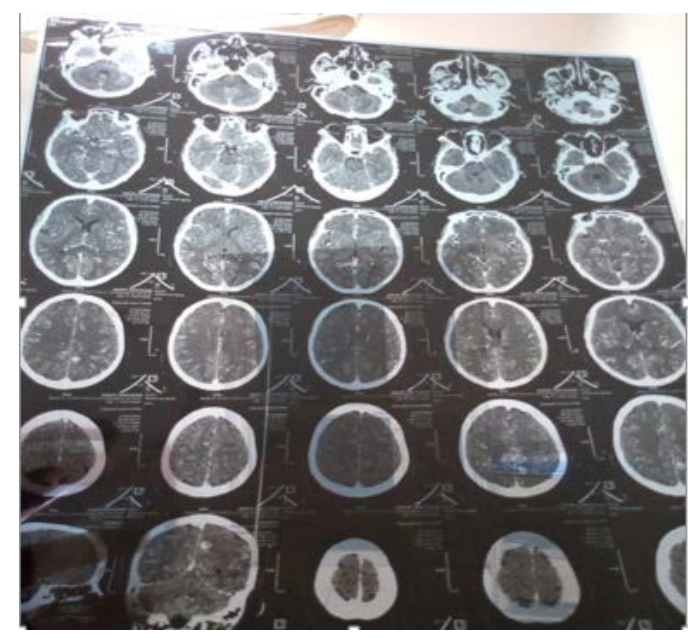

Figure1. Cerebral scanner.

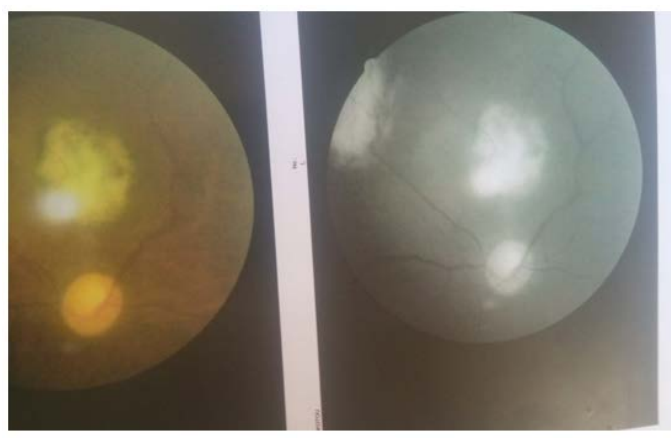

Figure 2. Photo of retinitis that is indicative of posterior uveitis.

possible to observe a decrease of the viral load. The antiviral protocol used is based on two nucleoside reverse transcriptase inhibitors, a non-nucleoside reverse transcriptase inhibitor (tenofovir-lamuvidine-efavirenz): 1compressed at night in bed and a symptomatic treatment based on depakine $500 \mathrm{mg} 1 \mathrm{com}$ pressed morning and evening and rehydration. Treatment of ocular involvement was instituted with the agreement of ophthalmologists namely: Timosol 1 drop in the eyes morning and evening and Diclocid $1 \mathrm{mg} / \mathrm{ml}: 1$ drop in the morning.

After the treatment the follow-up at one month shows a viral load at 24,000 copies to become undetectable at 6 mos of treatment. At the end of the anti-tuberculosis treatment the patient was declared cured.

\section{Discussion}

On the etiopathogenic level, ocular involvement is mainly due to reactivation of Mycobacterium tuberculosis (MT) favored by an alteration of the immune system (immunosenescence, chronic renal failure, immunosuppressive and anti-TNF treatments). Choroidal inflammation is caused by a cross-hypersensitivity reaction of the immune system to antigens of the choroidal or retinal pigment epithelium [2] [11]. The infection is mostly pauci-bacillary with a low yield of bac- 
teriological samples. Nevertheless, in rare cases, the infectious process is linked to hematogenous spread of Mycobacterium tuberculosis (MT) via the choroidal vessels, often associated with a pulmonary miliary chart.

We have described the case of a patient diagnosed with tuberculous uveitis during neuromenic tuberculosis/HIV1, a treatment failure. Tuberculous uveitis is the most frequent ocular lesion [2]. TB is the leading cause of OI of infectious origin in developing countries (60\% of infectious uveitis and $5 \%$ of all OIEs) [12]. The ULISSE study, which recently compared a standardized strategy to a free strategy for the etiological diagnosis of uveitis, shows that tuberculosis is responsible for $10.7 \%$ of the identified cause uveitis among the 676 patients included [13]. The prevalence of ocular TB is greater in immunocompromised patients [14] and asymptomatic ocular involvement is not uncommon in these subjects, justifying systematic ocular exploration [15]. This diagnosis was retained on the basis of clinical and paraclinical arguments.

\section{Conclusion}

Ocular involvement is a rare localization of tuberculosis, multidisciplinary management with ophthalmologists allowed us to diagnose this localization in this specific case.

\section{Conflicts of Interest}

The authors declare no conflicts of interest regarding the publication of this paper.

\section{References}

[1] Mjid, M., Cherif, J., Ben Salah, N., Toujani, S., Ouahchi, Y., Zakhama, H., et al. (2015) Epidemiology of Tuberculosis. Clinical Pneumology Review, 71, 67-72. https://doi.org/10.1016/j.pneumo.2014.04.002

[2] Gupta, V., Gupta, A. and Rao, N.A. (2007) Intraocular Tuberculosis-An Update. Survey of Ophthalmology, 52, 561-587. https://doi.org/10.1016/j.survophthal.2007.08.015

[3] Cochereau, I. (1997) Eye Damage during HIV Infection. Elsevier, Paris, 10 p.

[4] Fofana, M.A. (2005) Ophthalmological Manifestations during HIV/AIDS Infection in Children at IOTA. Medical Thesis, Bamako.

[5] Eye and Infectious Diseases. AIDS, 1-5.

[6] Hoang, P., Girard, B. and Rousselie, F. (1989) Eye and AIDS. Bulletin des societes dophtalmologie de France, 35-37.

[7] Chiou, S.H., et al. (2000) Ophthalmic Finding in Patients with Acquired Immunodeficiency Syndrome in Taiwan. Journal of Microbiology, Immunology, and Infection, 33, 45-48.

[8] UNAIDS/WHO (2011) Update on the HIV/AIDS Epidemic. Annual Report, Geneva.

[9] Lewallen, S. and Courtright, P. (1997) HIV and AIDS and the Eye in Developing Countries: A Review. Archives of Ophthalmology, 115, 1291-1295.

https://doi.org/10.1001/archopht.1997.01100160461014 
[10] Togo, A. (2013) Ophthalmological Manifestations during HIV/AIDS Infection in CHU-IOTA. Theses of Medicine, Bamako.

[11] Nazari, H., Karakousis, P.C. and Rao, N.A. (2014) Replication of Mycobacterium Tuberculosis in Retinal Pigment Epithelium. JAMA Ophthalmology, 132, 724-729. https://doi.org/10.1001/jamaophthalmol.2014.270

[12] Venkatesh, P., Gogia, V., Shah, B., Gupta, S., Sagar, P. and Garg, S. (2016) Patterns of Uveitis Atthe Apex Institute for Eye Care in India: Results from a Prospectively Enrolled Patient Data Base (2011-2013). International Ophthalmology, 36, 365-372. https://doi.org/10.1007/s10792-015-0128-9

[13] Parisot, A., Kodjikian, L., Errera, M.-H., Sedira, N., Heron, E., Pérard, L., et al. (2017) Randomized Controlled Trials for a Standardized Strategy for Uveitis Etiologic Diagnosis (ULISSE). American Journal of Ophthalmology, 178, 176-185. https://doi.org/10.1016/j.ajo.2017.03.029

[14] Heiden, D., Saranchuk, P., Keenan, J.D., Ford, N., Lowinger, A., Yen, M., et al. (2016) An Examination for Early Diagnosis of Disseminated Tuberculosis in Patients with AIDS. The Lancet Infectious Diseases, 16, 493-499.

https://doi.org/10.1016/S1473-3099(15)00269-8

[15] Cordero-Coma, M., Calleja, S., Torres, H.E., del Barrio, I., Franco, M., Yilmaz, T., et al. (2010) The Value of an Immune Response to Mycobacterium Tuberculosis in Patients with Chronic Posterior Uveitides Revisited: Utility of the New IGRAs. Eye, 24, 36-43. https://doi.org/10.1038/eye.2009.51 